\title{
BLOG LITERÁRIO: ALGUNS COMENTÁRIOS
}

\author{
Alamir Aquino Corrêa* \\ Marília Israel Rocha**
}

RESUMO: Se o conceito de literatura é marcado por discussões e reformulações ao longo da história, parece importante partir da ideia que "as escritas de si" presentes na "pós-modernidade" apontam para a revisão de algumas noções a respeito do ficcional e da literariedade presentes em textos que são veiculados na internet, especificamente o blog. A escrita de expressão subjetiva, recolhida muitas vezes apenas em diários íntimos, encontrou na internet um meio para fazer ecoar vozes antes silenciadas e, portanto, também terá destaque dentre os assuntos aqui discutidos, ao lado de reflexões sobre a canonicidade de textos e da configuração do blog como espaço de autorreferencialidade e de publicidade da escrita literária.

PALAVRAS-CHAVE: Blog. Literariedade. Escrita feminina. Pós-modernidade.

\section{Subjetividades contemporâneas}

Entre os constructos $^{1}$ que descrevem a condição pós-moderna, desconstrução, desterritorialidade, fragmentação e multiplicidade se afirmam como rearticulações constantes, tirando os sujeitos da zona de conforto onde prevalecem elementos bem definidos e estabelecidos pelas práticas sociais das comunidades pequenas e médias. Assim, é necessário ter consciência do papel da mídia na vida contemporânea naquilo que tangencia ou mesmo constitui a identidade individual e aquela coletiva, como se pode depreender da antologia de textos fundamentais sobre o assunto (DURHAM; KELLNER, 2006). Essas mudanças podem ser positivas ou negativas, dependendo do olhar, pois a vida na cidade de médio e de grande porte, no Brasil com maior peso a partir da década de 1950 com a migração do mundo rural para aquele urbano. Elas provocam no indivíduo uma sensação de

\footnotetext{
* Universidade Estadual de Londrina, Londrina, Brasil. Imeio: correa.alamir@gmail.com

** Universidade Estadual de Londrina, Londrina, Brasil. Imeio: m.i.mariliaisrael@gmail.com

1 Lembre-se aqui de De la grammatologie (1967), de Derrida, Anti-CEdipus (1972), de Deleuze e Guattari, La condition postmoderne (1979), de Lyotard, Simulacres et simulation (1981), de Baudrillard, The Consequences of Modernity (1990), de Giddens, Modernity and ambivalence (1991), de Bauman, e Postmodernism, or, the Cultural Logic of Late Capitalism (1991), de Jameson.
}

\section{(cc) BY-NC-ND}

Esta obra está licenciada com uma Licença Creative Commons.

Texto Digital, Florianópolis, Santa Catarina, Brasil, v. 11, n. 1, p. 420-444, jan./jun. 2015. ISSNe: 1807-9288. 
liberdade por um lado, questionando valores como religião e família, que une(ia) indivíduos ao redor de uma vontade específica de comunidade, e admitindo pluralidades que se pretendem anônimas ou menos visíveis; por outro, deslocam o indivíduo de sua tradição social, perdido ou afastado das ferramentas de controle e de suporte do grupo a que pertencia: família, bairro ou, mesmo, convicção religiosa (não é de outro tom os termos freguesia e paróquia).

Na esfera pública ou privada, o final do século $X X$ e o início do século $X X I$ são pautados pela transfiguração de paradigmas identitários. A situação sócio-histórica passa nesse momento por uma contínua reformulação, cercada de informações e tecnologias que se tornam obsoletas muito rapidamente, substituídas reiteradamente por tantas outras informações e tecnologias. Antes que se conclua uma ideia, já existem novas circunstâncias a serem levadas em consideração, tornando o trabalho de definir a si mesmo e o outro bastante difícil. Talvez seja possível pensar a pósmodernidade (ainda que um termo discutível) como a era da não-definição ou nãodeterminação, não pela falta de informações para sua figuração, mas pela enorme quantidade delas. É como se o excesso de opções e configurações ou, pelo reverso, pela ausência de uma confiabilidade de parâmetros (ou sua exigência) obrigasse ao indivíduo uma "não-identidade" ou identidade móvel ou descentramento do indivíduo, como se vê na percepção de Hall (2006). Nesse particular, Castells (2005, p. 17) afirma que a informação foi sempre base da sociedade, mas agora estamos a lidar com uma múltipla configuração reiterada pela microeletrônica, o que amplia desmesuradamente o número de informações.

Muito mais que o duplo (decorrente da dualidade romântica) ou a consciência de si (própria do reconhecimento das variações psicológicas) pelo espelho emocional ou social, a condição contemporânea (pós-moderna, líquida ou poder-se-ia dizer mais acidamente amorfa) se caracteriza pela falta de uma identidade ou por sua busca desesperada. De certa maneira, a ida/migração para a grande urbe, onde há mais oportunidades e locais de ser, também carreia uma dualidade: o desaparecimento ou esmaecimento das instituições de controle próximo (o vizinho, a família, a igreja, a rua, o bairro) e o fortalecimento da identidade singular. As comunidades de 
imigrantes nas grandes cidades internacionalizadas como New York, Paris ou Madrid se fazem percebidas em bairros, lojas e restaurantes (e mais recentemente escolas e igrejas), onde o imigrante se encontra com suas raízes perdidas pelo movimento do ter de sair e do querer ficar.

Talvez seja apropriado dizer que o momento contemporâneo é marcado pela maior dificuldade de pertença em face do excesso de coisas, e consequentemente nãotempo, pela impossibilidade da referência de partida. Em outros termos, a ausência de certeza ou de identidade se dá pela impropriedade do ponto de observação, vez que afirmar um nós, como na fala do eu imperial ou majestático, estabelece desde sempre uma posição de onde se fala com a autoridade daquele que fala. Essa circunstância tem sido problematizada em muito das discussões acerca do papel de construção e percepção da arte, especialmente se observada a Europa ocidental como conjunto referencial ou $\mathrm{o}$ ponto de partida. Os movimentos de descentramento, ao admitir outras proposições de fala, como no orientalismo de Said ou no hibridismo e na ambivalência de Bhabha, tornaram cada vez mais complexas as interações e as proposições de verdade.

Dentro desse contexto de destruição, pela perda de raízes seja lá por qual razão, e reconstrução de identidades, para realizar a pertença, a verdade parece menos importante que a própria palavra que a representa; tudo se torna viável desde que tenha possibilidade de aceitação, amplificando as possibilidades de criação de lendas urbanas ou, em termos mais contemporâneos, de efetivação de entes mediáticos. Essa instância de conformação tecnológica, considerada aqui desde o século XX, permite que um ser se faça "real" sem evidência de verdade, pela menção radiofônica, televisiva ou "internáutica", mascarado pelo distanciamento natural de outros na urbe imensa ou da imagem que se constrói midiaticamente, a desprezar a verificação do testemunho porque crível desde sempre em razão do meio em que se faz presente.

Esse fenômeno que não é novo, tradicionalmente encontrável nas construções míticas ou nas histórias de exotismo (como na expansão ultramarina), reveste-se 
agora da sua viabilidade (naquilo que se convencionou conceituar como o meio sendo a própria verdade ou mensagem). Lembre-se aqui da transmissão de The War of the Worlds em 1938, feita por Orson Wells na rede radiofônica Columbia Broadcasting System; o fato de ali estar, no rádio, dava ao texto a possibilidade e, consequentemente, a certeza de ser verdade. Talvez o maior acontecimento tecnológico dos últimos 50 anos, a chegada do homem à lua foi transmitida pela televisão em 1969, episódio ainda visto como possível farsa, mas em essência crível pelo próprio meio em que foi transmitido. Aliás, a televisão é quase um prolongamento de muitos de nós, fonte ininterrupta de informações e verdades, como propôs Beatriz Sarlo em Cenas da vida pós-moderna, ainda que o jornal impresso e a rádio ainda mantenham sua aura de verdade.

A identidade contemporânea tem sido, assim, uma busca constante, a se construir pela pressão imensa da "atualidade", contexto que provoca no indivíduo uma ansiedade acerca de sua existência reconfigurada a todo instante, errante e sem espelho de pertença. As redes sociais, na internet, mesmo quando eram apenas os bulletin boards da década de 1980, se tornaram esse local da configuração reiterada do indivíduo, a buscar incessantemente a si mesmo, sabendo de si e dos outros, talvez quase obsessão, por uma complexa falta de identidade. É como se o indivíduo contemporâneo precisasse de uma verdade que o construa, mas essa verdade se faz débil, frágil, volátil pela circunstância específica da instantaneidade das informações, inicialmente verdade, logo a seguir inexistência ou substituição. Fundamentalmente contemporânea e urbana, a destruir as fronteiras imensas e concretas de viadutos e arranha-céus, essa busca norteia a fundação de várias identidades ou de indivíduos com múltiplas ou fragmentadas identidades.

Não de outra sorte, nas redes sociais e naquilo que se convencionou chamar de internet ou de web (com a expressão "está na rede" ou "está na web"), fisicamente computadores, servidores, centros de dados (todos os nós) e cabos (constituintes físicos da rede a interligar os nós), há um conjunto de construções textuais, quer sejam páginas, blogs ou fotologs, onde ocorre o surgimento e, logicamente, o fenecimento de várias identidades "virtuais", correspondendo ou não a verdadeiras 
ou reais identidades, sem que essa circunstância de compromisso entre representação e verdade tenha qualquer importância. E sem sobra de dúvida, a "internet" se tornou parte do tecido social (CASTELLS, 2003, p. 255), a configurar-se nele como voz e como espaço de audição dessa voz.

Nesse momento, marcado pela dúvida sobre as certezas talvez iniciada pela morte de Deus proposta por Nietzsche, ao se observar a produção literária, até recentemente feita em papel em sua quase totalidade, vê-se que esse suporte tem sido discutido enquanto processo editorial e enquanto produto, principalmente acerca de sua viabilidade. A liberdade ensejada pela produção individual, como fez a geração mimeógrafo, obtendo não só as ferramentas para a editoração, mas também a sua interação com o leitor, encontra caminho no mundo digital para sua visibilidade sem os filtros editoriais e críticos. Esse espaço se dá por várias vozes antes mudas, esquecidas ou silenciadas, que se mostram quase sempre desesperadas por uma identidade pela exposição de si ao outro, por vezes como sugere Castells (2012, p. 19-20) a possibilitar politicamente o surgimento de novas coletividades.

Assim, pretende-se nesse texto tratar, mesmo que tangencialmente, de uma circunstância particular contemporânea. $\mathrm{Na}$ internet, as mulheres revelam na produção digital uma consciência maior de si, por vezes descompromissadas com seus papéis ditados pelo patriarcalismo ou mesmo a discutir se esse descompromisso é mesmo necessário, talvez a colocar em xeque a libertação das estruturas de controle social, particularmente em uma sociedade de tradição iberojudaico-cristã. Essa revelação se dá em materiais que se fazem mais visíveis com o surgimento da internet, em particular o formato do blog, pela maior possibilidade da voz e da interação social entre diferentes pares (e por vezes ímpares). E, dessa maneira, revelam ou parecem revelar várias das subjetividades que se organizam como busca de identidades em crise, como parte de um contexto social maior da sociedade que se faz diferente, marcada pela mudança, ou, em outros termos, como se percebe na visão proposta por Stuart Hall acerca da sociedade contemporânea: 
Assim, a chamada crise de identidade é vista como parte de um processo mais amplo de mudança, que está deslocando as estruturas e processos centrais das sociedades modernas, abalando os quadros de referência que davam aos indivíduos uma ancoragem estável no mundo social. (HALL, 2006, p. 7).

\section{Literatura contemporânea: identidades e autoridades}

Uma das formas de tentativa de construção ou reconstrução de identidade individual ou coletiva (gênero, etnia, idade etc) se dá na produção literária; claro que as outras artes (música, dança, cinema e vídeo) também lidam com essa mesma fragmentação do indivíduo pela perda de território, de referencial, de parâmetro, em suma, de certeza. Relacionadas ao universo literário, direta ou indiretamente, autoria, produção, circulação e recepção do texto são merecedoras da reflexão acerca de seus conceitos diante das circunstâncias advindas do cenário pósmoderno. De fato, talvez fosse mais válido pensar sobre o que torna literário um texto ou onde reside a sua literariedade de um texto, algo que tem sido motivo de preocupação continuada, mas sem resultados definitivos (JUVAN, 2000). Ainda que estas perguntas sejam foco de inúmeras discussões na teoria literária dos últimos trinta ou quarenta anos, as contingências da contemporaneidade demandam esses questionamentos. Interessantemente, esse assunto já faz parte das primícias dos cursos de Letras, como se percebe em Márcia Abreu, quando afirma que os textos considerados pertencentes à "Alta Literatura" adquirem esse status ao serem assim julgados por "instâncias de legitimação", as quais

são várias: a universidade, os suplementos culturais dos grandes jornais, as revistas especializadas, os livros didáticos, as histórias literárias etc. Uma obra fará parte do seleto grupo da Literatura quando for declarada literária por uma (ou de preferência, várias) dessas instâncias de legitimação. Assim, o que torna um texto literário não são suas características internas, e sim o espaço que lhe é destinado pela crítica, e, sobretudo, pela escola no conjunto dos bens simbólicos (ABREU, 2006, p. 40).

Ao determinar quais textos são dignos ou não de compor o cânone literário, em geral refletindo a postura de um grupo dominante, que se organiza como legitimado e como legitimador, como adverte Frank Kermode (1979), estes institutos ou 
instâncias emitem juízos de valor que se tornam um padrão a ser seguido. Mas se essas instâncias são a salvação dos "bons textos" e "bons autores", como quer Harold Bloom em $O$ Cânone Ocidental, quem nos salvará das instâncias de legitimação, no sentido do seu absoluto? Em outros termos, a bitola ou o crivo que qualifica ou autentica a produção literária pode, em tese, inviabilizar, por todos os meneios de sua atuação, que vozes sejam ouvidas, sem jamais alcançar o leitor? Nesse sentido, ao se introduzir a disciplina de literatura no currículo escolar, difundiu-se a ideia de que o texto literário, considerado assim por aqueles credenciados socialmente para tal tarefa, é um bem comum ao ser humano. Enquanto herança cultural caracterizada como importante, deve ser lida por todos da mesma maneira; aparece na escola básica e também em processos seletivos de várias universidades, em forma de textos sobre os quais se formulam questões de múltipla escolha que permitem uma resposta única, como uma "interpretação mecanizada" ou uma verdade institucionalizada.

Em texto criticamente contumaz, Leyla Perrone-Moisés afirma que o projeto de estabelecimento de um cânone literário, em síntese do que vem a ser ou não literário, não se baseia em noções acadêmicas, mas, sim, em princípios de modernidade (PERRONE-MOISÉS, 1998, p. 12). E a autora prossegue: "Sem um conjunto de valores, qualquer cânone (prescrito por autoridades, como no classicismo, ou eleito pelos interessados, como no romantismo e na modernidade) é contestável. É essa poética, e consequentemente o cânone que a ela corresponde, que se encontram hoje em via de dissolução" (PERRONE-MOISÉS, 1998, p. 173). Ela acredita que, diante da fragmentação contemporânea, os critérios que balizam o que deve ou não ser considerado literatura estão se perdendo. O surgimento dos Estudos Culturais em oposição aos Estudos Literários deu espaço a obras e/ou textos "não merecedores" de estudos acadêmicos, já que seus autores não formam parte do cânone ocidental. Para muitos críticos e professores universitários, tais textos não conteriam a chamada literariedade, a ser determinada por questões exclusivamente relacionadas a elementos encontráveis nas obras, quer de maneira formal quer de maneira intencional como propôs Derrida, mas que parece verdadeiramente surgir sim da ação desse texto sobre aquele que o lê. Nesse nível 
de discussão é essencial perceber não só a pluralidade de não-identidades, enquanto negação da certeza da arte, mas também a pluralidade de espaços de produção.

\section{Literatura em ambiente digital}

A internet tornou ínfimas as distâncias e boa parte a informação antes inacessível perdeu muito de suas proibições e interdições (como a visita ao acervo de uma biblioteca a milhares de quilômetros). A interação entre usuários permite o estar perto ou próximo sem estar e a ubiquidade depende tão somente de um ponto inicial de acesso, a realizar quase a frase divina do que era, é e que há de vir. Por conjugar vários interstícios e nós, invisíveis em sua maioria, perto e distantes ao mesmo tempo, marcados por camadas de visualidade e permissão de acesso (como a web, a deep web e a hipotética marianas web), a internet se faz um meio ideal para que se possa falar em dinamismo comunicacional, onde não há uma definição absoluta e concreta a singularizar e hierarquizar sujeitos e objetos, agora tornados pontos e contrapontos complementares e suplementares entre si, destruídos o seu momento e a sua circunstância de origem. Essa qualidade, aliada às tecnologias da informação, faz com que o hipertexto encontre na internet, mais do que nunca, um "habitat favorável" por sua volatilidade e quase abstração (pela qualidade de seu suporte):

O que torna o hipertexto diferente, o que o destaca do documento em papel mais conceitualmente interligado, é que, no hipertexto, os links são 'máquina de apoio'. Quando o leitor seleciona um link de hipertexto, o 'movimento' entre os dois nós ocorre automaticamente. É por esta razão que o advento de hipertexto teve que esperar para a combinação de potência e exposição incorporado no computador moderno. (MCKNIGHT, DILLON \& RICHARDSON 1991, p. 3, apud CORRÊA, 2006, p. 32, tradução nossa $)^{2}$

\footnotetext{
${ }^{2}$ What makes hypertext different, what sets it apart from the most conceptually inter-linked paper document, is that in hypertext the links are 'machine supported'. When the reader selects a hypertext link, the 'movement' between the two nodes takes place automatically. It is for this reason that the advent of hypertext has had to wait for the combination of processing power and display embodied in the modern computer.
}

Texto Digital, Florianópolis, Santa Catarina, Brasil, v. 11, n. 1, p. 420-443, jan./jun. 2015. ISSNe: 1807-9288. 
As múltiplas conexões, as interações, a ausência de singularidade, tudo leva para o não-reconhecimento do lugar e do tempo, cujas existência e experiência se fazem sem efetivação, quer dizer, a hipertextualidade é a própria não-identidade, ou o que Jameson chamou de hiperespaço pós-moderno, por sua ausência de contornos, limites e definições. Isso se dá bastante em símile com a ruptura das fronteiras geográficas e culturais estabelecidas pelas várias interconexões oriundas do advento da "sociedade da informação" (ainda que se possa dizer que toda sociedade sempre se baseou no conceito do domínio da informação).

Ao par dessa atitude libertária, no caso específico da literatura disponível na internet, é necessário reconhecer algumas diferenças de produção, construção e recepção. A produção literária transposta para o meio digital é denominada de literatura digitalizada; também chamada de ergódica (AARSETH, 1997) ou eletrônica (HAYLES, 2008), a literatura digital seria aquela que existe a partir de sua construção em meio digital, ainda que possa haver nuanças em tais denominações ${ }^{3}$. Mesmo algo cujo suporte final seja o papel contém uma marca digital (HAYLES, 2008, p. 43), por ter sido construído dentro de ambiente digital (processadores de texto, diagramações, revisões etc). No caso do conceito de "literatura digital", há de se pensar primeiramente na questão da adição do termo "digital" à palavra "literatura", quer dizer, a passagem do suporte impresso para o suporte tela, a exigir muito mais do que o uso da língua (logo, linguagem) e sua codificação gráfica, em razão de seu processamento - traduções em duas vias (homem-máquina e viceversa), iterações, compilações, execuções etc. A partir daí, a produção e a fruição de leitura não estão limitadas mais ao material escrito, por serem digitalmente possíveis objetos constituídos de palavras, sons e imagens (com ou sem movimentação), e tampouco ao objeto percebido enquanto uma unidade singular, como o livro.

3 Literatura ergódica é aquela em que o leitor precisa escolher para onde ir (navegar) ou estabelecer novos processos de leitura, configurando o texto; literatura eletrônica é aquela nascida em meio digital.

Texto Digital, Florianópolis, Santa Catarina, Brasil, v. 11, n. 1, p. 420-443, jan./jun. 2015. ISSNe: 1807-9288. 
O fato de estarem dois pontos (nós) unidos por um cabeamento com ou sem fio (ainda que paradoxal a afirmação) resulta, por haver a rede, em vários processamentos, incluindo sistemas operacionais diferentes (por exemplo: Linux, FreeBSD Mac OS X, Windows NT e Android). Essas ligações e reconfigurações engendram por consequência uma múltipla vocalidade; quer dizer, o texto construído por um autor poderá ser alterado e devolvido pelo fruidor à de recepção de outros fruidores. O sistema autor-obra-público geralmente unidirecional, com as camadas de organização e distribuição (como editor, gráfica, livreiro, divulgação, crítica, escola), por si só, se tornou insuficiente, gerando um conjunto novo de autoresobras-públicos, uma "literatura em rede", termo importante para o presente estudo (Gendolla; Schäfer, 2007, p. 24-27), pelas múltiplas relações entre autores, leitores, textos escritos e textos lidos e textos comentados.

\section{Das qualidades do blog}

A palavra blog é uma versão truncada de weblog, variantes são fotolog ou videolog (hoje já em desuso, substituído pelo canal do Youtube), a mimetizar o diário de bordo marítimo, a contabilidade do comércio, a crônica de guerra; sua voz autoral é a de um autor ou blogger/blogueiro, podendo assumir o caráter de voz de pequenas coletividades. Em síntese, seu formato é de uma sequência de postagens de tom coloquial, organizadas de maneira cronológica reversa, permitindo geralmente uma interatividade com os visitantes, embora haja blogs que não a permitem e, em geral, comentários passam pela edição ou autorização do blogueiro para sua visualização. O jornal tem adotado o blog como forma de transposição das colunas opinativas; há também os microblogs, como o Twitter. No conjunto, pode ser uma plataforma de exercícios e de alavancagem editorial (MATOS, 2009) e de busca de outras experiências, a formar uma comunidade de leitores-escritores (DI LUCCIO; NICOLACI-DA-COSTA, 2010b, p. 100-106).

De acordo com Luiza Lobo, em Segredos Públicos - os blogs de mulheres no Brasil, esses espaços de exposição diária ou com certa frequência têm um caráter de inovação: "Um dos aspectos mais inovadores dos blogs em relação aos diários 
tradicionais é aceitarem comentários de forma interativa, o que os torna um veículo da mídia, assim como uma produção pessoal e coletiva" (2007, p. 22). As identidades participantes desse diálogo, produtores e receptores, podem ter ou ser vozes absolutamente ficcionais, como seria o caso de um robô interativo construído com a finalidade precípua de respostas (por inteligência artificial ou por predisposição aleatória) ao que surgir como reação ao texto do blog (GENDOLLA; SCHÄFER, 2007, p. 31-33). Ainda que esse processamento de dados seja possível somente em ambiente digital, está a replicar o sistema de notas, réplicas e tréplicas no ambiente de jornais e revistas, como foi o rumoroso caso a envolver a discussão sobre arte e moralidade a partir da obra de Oscar Wilde (MASON, 1908).

Como descrição do blog, o termo técnico descritivo mais adequado parece ser "hipertexto", por este permitir que sejam associados outros elementos a sua conformação e múltiplas leituras em diferentes direções, ainda que não seja um expediente novo: "O hipertexto, aparentemente, não é nenhuma novidade, já que se trata basicamente de um texto marcado por um sistema de remissivas. Uma estrutura que sempre existiu, ainda que de forma mais ou menos intuitiva" (CORRÊA, 2006, p. 32). Em essência, os blogs permitem que qualquer indivíduo (ou indivíduos) se expresse $(\mathrm{m})$ por meio de textos (aqui o termo a englobar palavra, som, imagem estática ou em movimento), que podem ser ou não "reais", no sentido de corresponderem a uma referencialidade "carnal" ou estarem vestidos de uma ficcionalidade. Esse caráter ficcional, enquanto construção de identidade, tampouco é novo, se observado o conjunto bastante razoável e conhecido de textos jornalísticos assinados por pseudônimos. Embora haja várias discussões acerca do blog enquanto grande árvore de gêneros textuais, conforme relata e discute Magnabosco (2010), para este artigo, o blog será percebido na sua possibilidade de gênero literário, espécie de diário aberto, formado por histórias que passam possível e obviamente pelo crivo pessoal de quem as escreve, um território/espaço que acolhe visitantes que podem se tornar também autores (na área de comentários). Há várias preocupações sobre o blog incluindo percepções de gênero, de condição pública e privada, e de seu armazenamento, como se ocorreu em Seminário realizado em 2011 pelo Réseau des services d'archive du Québec, do qual se 
destaca aqui um descritivo sobre a tipologia dos blogs e seu estrato de intimidade (ZELLER, 2011).

Mesmo se ficcionais ou não, enquanto relatos pessoais, eles mantêm em suas vozes o tom de revelação íntima (RODRIGUES, 2004) e, paradoxalmente, se mostram públicas, mantendo uma história de si e ao mesmo tempo correspondendo à necessidade hipotética do leitor (visitante do blog) por um verismo ou estabelecendo uma possível correspondência com uma realidade palpável ou encontrável, agindo naquilo que se viu como "literatura de rede"; a concepção de rede é mais importante pelas interconexões a unir autores e leitores (no plural!), como se percebe em estudos sobre blogs de luto (MICALIZZI, 2009). Claro está que essa revelação íntima pode ser simplesmente a opinião sobre determinado assunto, como o resultado de uma partida de futebol ou sobre a novela das oito.

Por outro viés, há nesses textos aquilo que Barthes chamava de biografemas: "Essas cápsulas de subjetividade que fragmentam o eu em pequenas partículas servem para aproximar esse eu de um determinado grupo de leitores" (apud SCHITTINE, 2004, p. 194). As subjetividades contidas nos textos de blogs pessoais tendem a provocar o público leitor que também busca uma identidade, tanto de idolatria no caso de seguidores de personalidades famosas quanto de simetria quando se vê diante de situações que se assemelham ao seu próprio mundo e a sua experiência íntima. Nos blogs, os leitores podem estabelecer relações de cumplicidade (ou de discordância) com todos aqueles que escrevem algo no blog. $O$ relato de experiências, que antes estava restrito aos diários íntimos muito bem guardados, afinal continham segredos, agora está exposto na rede e é passível de discussão. O caráter da intimidade é preservado, particularmente pela condição de sua possível verdade, aqui importante o lado da sua possibilidade, mas não mais o caráter do secreto, quando se trata de um diário virtual disponível em linha (online):

O contorno aberto e impreciso do "espaço biográfico" - na verdade, uma espaço/temporalidade - não cessou de expandir-se no marco da globalização, alentado pelo desdobramento sem fim das tecnologias: multiplicidade de formas, gêneros, estilos e suportes, que tanto imitam como 
contrariam a seus antecessores, ocorrências mediáticas, acadêmicas, literárias, cinematográficas, nas artes visuais, na Internet, práticas que alteram decisivamente os umbrais entre o público, o privado e o íntimo e que dão conta, mais além da análise específico de seus gêneros, de una verdadeira reconfiguração da subjetividade contemporânea (ARFUCH, 2014 , p. 70 , tradução nossa. $)^{4}$

A pós-modernidade desenha, então, o seguinte cenário: a intimidade não é mais secreta ou revelada apenas para aqueles próximos como os familiares; ela está agora a serviço de qualquer um que acesse aquela página na internet, como reconfiguração da subjetividade. Esse ângulo íntimo atrai o leitor que busca um verismo, de tal sorte que pessoas anônimas e comuns podem vir a ser uma celebridade blogueira a partir do número de leitores e repercussão das ideias contidas nos seus textos, ou de uma construção de identidade, caso particular dos escritores/leitores/blogueiros (DI LUCCIO; NICOLACI-DA-COSTA, 2010a) em ação de mutualismo literário, se é que se pode usar essa imagem.

Mas, fica a questão, observada essa condição opinativa e coloquial a qualificar o blog, próximo da crônica de um Drummond ou de um Rubem Braga, seria possível (além da ficcionalidade compositiva de autoria e de interação) ser o blog algo literário? A sua qualidade literária pode ser testada? Por primeiro, não há um teste padrão da literariedade, afinal todo texto pode ser literário ou não - depende muito do que se quer e do que se percebe como literário. Como demonstrar a literariedade de um Dostoiévski ou de um Mann? O que torna algo literário além da afirmação social de que um texto é literário? Se o argumento for de uma perenidade ou de um valor estético do texto que ultrapasse o seu grau de compromisso imediato com os fatos recentes, que garantia de permanência há para qualquer texto? Lembre-se que essa permanência é fruto da vontade futura, que pode canalizar outros interesses a negar mesmo valor aos objetos antes tidos como canônicos e depois, mesmo se considerados como literários, relegados a uma plana inferior como tem sido o caso

\footnotetext{
${ }^{4}$ El contorno abierto e impreciso del "espacio biográfico" - en verdad, una espacio/temporalidad - no ha cesado de expandirse en el marco de la globalización, alentado por el despliegue sin fin de las tecnologías: multiplicidad de formas, géneros, estilos y soportes, que tanto remedan como contrarían a sus antecesores, ocurrencias mediáticas, académicas, literarias, cinematográficas, en las artes visuales, en Internet, prácticas que alteran decisivamente los umbrales entre lo público, lo privado y lo íntimo, y que dan cuenta, más allá del análisis específico de sus géneros, de una verdadera reconfiguración de la subjetividad contemporánea.
}

Texto Digital, Florianópolis, Santa Catarina, Brasil, v. 11, n. 1, p. 420-443, jan./jun. 2015. ISSNe: 1807-9288. 
de Coelho Neto. Se for possível responder firmemente a qualquer dessas questões, talvez se possa qualificar a produção em ambiente digital como literária ou não literária.

Os blogs literários, a se aceitar o adjetivo, pertencem à "literatura em rede", por sua qualidade ficcional de construção de uma identidade que fala diretamente com um público (ou a ele se dirige), em jogo de cumplicidade e intervenção, e por sua recursividade (como forma de autoenfrentamento e crítica mútua entre autores e leitores, destruído o ritual unidirecional de condução das verdades). A retomar "inovação" como um dos elementos apontados por Perrone-Moisés como integrante do que se pode chamar de "Grande Literatura", por inovar a relação de produção e recepção, o blog literário precisa carregar elementos que possam torná-lo literário, ainda que a academia se posicione como reticente em relação a essa possibilidade.

\section{Os blogs como escritas de si}

Os blogs com roupagem literária, aqueles que pretendem uma qualidade literária, ainda que discutível sua "literariedade", são espaços que parecem conter fragmentos da vida de quem o escreve. Entre os gêneros textuais que se enquadram em "escritas do eu" como memórias, ensaio, ou romance autobiográfico, o blog contém um pouco de cada um desses gêneros, uma espécie de colcha de retalhos. A partir do termo "autoficção" que aparece no romance Fils (1977) de Serge Doubrovsky, talvez o blog literário se assemelhe mais a essa proposição autorreferencial e ficcional: "um meio caminho entre a realidade e a ficção contaminado pelas duas, um híbrido entre o relato verdadeiro e o relato mentiroso" (SCHITTINE, 2004, p. 192); em outros termos, um texto que teria uma qualidade ficcional, lembrando-se aqui da "verdade das mentiras", na imagem proposta por Vargas Llosa como título de seu livro de ensaios. Dessa maneira, há de se reconhecer a possibilidade real de haver no blog uma qualidade literária que a ser aceita com menos reservas. 
Se o blog literário se constitui de autoficção, diário íntimo e ao mesmo tempo público, no qual a/o diarista conta pequenos fragmentos de sua vida, o leitor ou interator (pela qualidade de conexão/interação com outros leitores e com o próprio blogueiro) não tem qualquer certeza de sua condição de verdade ou de pressuposição de entidade ficcional por si só; tais textos podem não corresponder ao que realmente sucede na vida do/a(s) autor/a(s) do blog e tampouco podem ser percebidos exclusivamente pelo mecanismo de suspensão da descrença proposto por Samuel Coleridge. Pelas ferramentas disponíveis nos blogs, os leitores não apenas se aproximam do autor/blogueiro pela leitura de seus textos, por vezes supondo encontrar um verismo, no sentido de ter um contato real com o autor, mas podem ter uma atuação sobre o que está lá exposto e interagir com outros leitores (nas respostas aos comentários, gerando réplicas e tréplicas), até mesmo ter uma resposta subjetiva de um autor/blogueiro, pessoa/identidade real ou ficcional com a qual o leitor pode interagir. Essa relação textual se torna hipertextual, especialmente pelo tipo de construção textual e relacional, que admite vínculos com outros textos e nós hipertextuais, feitos tanto pelo blogueiro quanto por seus leitores/interatores. Nessa condição, o hipertexto digital se constitui em possibilidade de discussão da autoridade, aquela das instâncias legitimadoras, por relacionar-se um texto a outros pontos de configuração e reinvenção textual a debilitar a função autenticadora do sistema canônico, tornando-o obsoleto ou desimportante. Da mesma forma, a noção ou percepção da literariedade, aquela qualidade que seria tão própria, exclusiva e particular ao texto literário, passa a ser identificada e aceita diretamente pelo leitor comum (ou leitor letrado), sem a égide do sistema editorial, crítico e escolar que restam desconcertados em suas verdades (BUURMA; HEFFERNAN, 2012).

Nesse aspecto, há de se considerar a escrita de si realizada no blog. Ela pode indicar uma busca de si, na qual a construção da identidade individual se dá por meio da identificação com o outro. O termo "escrita de si", no mundo digital, tem já larga tradição, mas não veio do mundo literário, embora tenha sentido no que se entende como autoficção. A ideia daquele que escreve a si mesmo surge com os "vírus", ou seja, códigos capazes de replicarem-se, ou escreverem a si mesmos, criarem a si mesmos, sem que aqui seja importante ou fundamental descrever a 
trajetória histórica do conceito. A expressão "escrita de si" surge em texto de Azevedo (2007), ganhando outros contornos: "crônica de si", "auto-exposição de si" e "figuração de si"; para Viegas (2006), haveria uma "invenção de si".

A subjetividade presente no ciberespaço ganha território nos blogs, muitas vezes angariando "leitores-fãs" que encontram ali um espelho; assim, pode-se pensar que a literatura contemporânea (ou que se apresenta como texto literário) em ambiente digital se vale hoje de uma "vitrine virtual" na qual a "publicização" (no sentido de tornar público) do "eu" como matéria de ficção ou relato tem lugar privilegiado. Os episódios autobiográficos desenvolvidos nos meios midiáticos (entrevistas, perfis, relatos de autoajuda, testemunhos e reality-shows) atraem a atenção do público tornando pública a intimidade do indivíduo. De acordo com AZEVEDO (2007):

Se um surto de 'umbiguismo' parece ter invadido a rede, talvez seja possível pensar essa auto-exposição de si em relação com o seu suporte. Afinal, os relacionamentos e as próprias identidades nunca foram tão questionados quanto o são desde o surgimento da internet. Essa desconfiança em relação ao eu que se mostra através de bits pode dar uma dica de que é possível desviarse da ingenuidade de um sujeito transparente para pensar em uma escrita que cultiva ambigüidades, apostando em um efeito-sujeito. (AZEVEDO, 2007, p. 47)

A atração do público por textos que privilegiam a subjetividade é pertinente quando se pensa em algumas obras canônicas, ao longo da história da literatura, que mesclam a ficção e os fatos biográficos (além do contexto histórico) da vida do autor ou pelo menos do seu narrador. No caso do gênero romance e tomando as palavras que iniciam a célebre narrativa de Miguel de Cervantes, "En un lugar de la Mancha, de cuyo nombre no quiero acordarme...", alguns teóricos arriscam-se a dizer que Cervantes, em El Ingenioso Hidalgo de Don Quijote de la Mancha, inaugura dois gêneros: romance e autobiografia: "Ao empregar o discurso autobiográfico em Dom Quixote e proceder a individuação do personagem, [...] Cervantes criou ainda outro gênero, o romance intimista, baseado no eu, cheio de verve e emoção, típico do povo espanhol" (LOBO, 2007, p. 92, grifo da autora). 
Alguns séculos adiante e direcionando o olhar para a literatura brasileira, é notável como a narrativa em primeira pessoa presente em um romance até hoje causa polêmica, justamente pelo tom pessoal, quase confessional que lança a questão: Capitu traiu ou não Bentinho? Dom Casmurro é um romance cujo mistério ou indecidibilidade se dá justamente por ser narrado em primeira pessoa pelo personagem Bento Santiago, que conta uma história pelo prisma de suas impressões a respeito de sua amada Capitolina; é esse conjunto narrado que desperta tanta a atenção, por ser similar ao que se viu em Othello, mas centrado na figura do homem que duvida do que sabe - talvez espelho da vida de todos nós, incapazes de estabelecermos qualquer verdade até mesmo sobre nossa própria identidade. Não fosse Bento Santiago o narrador dessa trama, e ainda que pairasse a dúvida da traição conjugal, haveria uma obsessão quase coletiva sobre Capitu possuir "olhos de ressaca"? Vários outros exemplos de obras canônicas com tom pessoal e/ou que são inspiradas basicamente nas vivências de seus autores e/ou narradores poderiam ser elencadas nesse aspecto. Escrever sobre si mesmo (ou fingir ser alguém que escreve sobre si mesmo) não é, obviamente, uma novidade no mundo literário.

No entanto, a afirmação identitária própria do blog, enquanto escrita de si, indica não apenas um novo tipo de fazer literário, marcado pela subjetividade, mas principalmente a publicidade possível, no sentido de tornar esse eu público e visível, a expor uma escrita muitas vezes só encontrava como lugar o fundo de uma gaveta ou baú. Dessa forma, por seu baixo custo e por ultrapassar os crivos editoriais existentes para a publicação em papel, o blog se torna espaço especial para as mulheres se afirmarem como sujeitos autônomos, sujeitos que fazem parte de uma comunidade letrada, criativa e crítica e que finalmente podem ser vistos e ouvidos por qualquer outro que faça parte dessa comunidade. Assim, deixam de ser excluídas pelo mercado editorial para se tornarem protagonistas de suas histórias e de sua produção literária, independentemente de se aterem ou não a premissas de "bom comportamento" de linguagem (seja lá o que pode ser visto como "bom"), algo que lhes garantia, se tanto, algum espaço editorial. 
Se "somos usados pela linguagem tanto quanto a usamos" (LAKOFF, 1973, p. 13), ao se observar a escrita feminina, o que inclui a trajetória das mulheres e a luta por seu espaço na sociedade (desde a alfabetização até a participação política, incluindo a busca por direitos iguais), faz-se necessário estudá-la em si, considerando que a escolha da forma de expressão das mulheres é guiada por uma forma particular de pensar. Consequentemente, o modo como sentem o mundo se refletirá na maneira de se expressarem, pautando assim uma escrita de gênero. A escrita feminina, especialmente aquela literária, permite por sua ficcionalidade e autorreferencialidade uma condição particular, aquela da revelação íntima modulada pela subjetividade:

Se é verdade que nossos sentimentos sobre o mundo matizam o modo como expressamos nossos pensamentos, então podemos usar nosso comportamento linguístico como um diagnóstico de nossos sentimentos sobre as coisas, pois frequentemente podemos interpretar nossas ações ou percepções de acordo com nossos desejos, distorcendo-as conforme nossa conveniência (LAKOFF, 1973, p.14). Um subgênero particular desse contexto é o chick-lit (ou literatura para mulheres), ou o texto direcionado ao público feminino, na longa tradição burguesa do entretenimento de rodapé, típico do folhetim. Lembre-se aqui de Little Women (1868) de Louisa May Alcott, como obra voltada para a documentação da vida íntima e doméstica das mulheres, cuja sequência foi o Good Wives, a segunda parte da obra, possivelmente remediada pela série televisiva The Good Wife; há de se lembrar também de Bridget Jones's Diary (o livro, o filme, a sua sequência, o seu blog ${ }^{5}$ ), por seu largo impacto mediático, cujas origens podem ser buscadas na literatura epistolar do século XVIII, especialmente aquela de tom confessional. A qualidade geral desse material contemporâneo do chick-lit é de certa independência e ousadia, ainda que pautado quase sempre nas aventuras e desventuras de mulheres em face das exigências e das oportunidades da vida contemporânea.

\footnotetext{
${ }^{5}$ http://bridgetarchive.altervista.org/ Texto Digital, Florianópolis, Santa Catarina, Brasil, v. 11, n. 1, p. 420-443, jan./jun. 2015. ISSNe: 1807-9288.
} 
Realmente, as histórias não são mais escritas por moças bem comportadas, no sentido de agirem conforme os ditames editoriais, mas por mulheres que pretendem se expressar sem peias em uma mídia de alcance global, como se pode ver por exemplo nas narrativas em "Adorável Psicose", de Natalia Klein ${ }^{6}$, no blog de Luisa Accorsi $^{7}$, e no "Manual Literário para amar os homens ou não", de Ronize Aline ${ }^{8}$. A mesma liberdade admite também a sua evanescência, vez que um sítio com muitas visitas e até certa longevidade pode desaparecer de um dia para outro, como parece ser o caso de Accorsi, ou de sua fragilidade ou "amoldabilidade", como é o caso de Aline.

É de destacar o blog "Adorável Psicose" de Natália Klein devido ao sucesso alcançado na esteira de vários outros blogueiros já estudados por Azevedo (2007). Klein começou escrevendo apenas para amigos e com o tempo ganhou milhares de seguidores, contando principalmente suas desventuras como mulher solteira à procura de um relacionamento pelas noites cariocas e as consequências (quase sempre desastrosas) em um tom bem-humorado. Depois de algum tempo, foi convidada a adaptar os textos para um roteiro de série televisiva. O êxito de "Adorável Psicose" como blog e como série é resultante de uma confluência de fatores já mencionados aqui: a demanda do público por textos de caráter subjetivo, a identificação dos sujeitos contemporâneos com as angústias expostas por Natalia Klein e a facilidade de acesso que a internet trouxe para quem escreve e quem lê.

Por outro lado, há uma produção em blogs que se faz da inserção direta de poemas em meio digital, sem que esse material usufrua de algo mais além da estrutura compilativa e aditiva do blog. Quer dizer, o espaço de produção amealha várias produções individuais, sem nenhum rasgo de ousadia além da inserção de fotos e outras imagens a dar contexto ilustrativo ao poema; enquanto "antologia", permite um espaço de visibilidade. O caso do blog Maria Clara9, já estudado por Fernandes (2011), é exemplar desse comportamento. Hospedado em Blogspot, reúne a produção de doze mulheres, com um total de 288 poemas (até maio de 2013, data

\footnotetext{
${ }_{7}^{6} \mathrm{http}: / / \mathrm{www}$.adoravelpsicose.com.br/

${ }^{7}$ http://www.sonhosdecrepom.com.br/

${ }^{8} \mathrm{http}: / /$ www.ronizealine.com/2014/09/manual-literario-para-amar-os-homens-ou-nao.html

${ }^{9}$ http://mariaclara-simplesmentepoesia.blogspot.com.br/
} 
da última postagem), com maior grau de produção em 2010 (134 poemas). resultado maior desse blog foi a publicação em papel de Maria Clara: uniVersos femininos (2010).

Como se viu, os sujeitos contemporâneos encontram no ciberespaço, nas redes sociais e, mais especificamente, nos blogs um conjunto de elementos que favorece suas representações individuais e coletivas. Ao mesmo tempo, esses sujeitos se representam evidenciando o caráter plural e público da internet, que dispensa qualificações e dá a todos a possibilidade de escolha sobre o que escrever e o que ler, independentemente do local em que se encontram, voltando àquela ruptura já visualizada por Jameson. Além disso, o blog representa uma rebelião não apenas contra as normas cultas da escrita, mas uma rebelião no que se refere à própria estruturação de textos escritos por mulheres, pois essas escritoras:

\begin{abstract}
Abolem as regras do bom estilo, das normas gramaticais, da ortografia, do vocabulário cuidado, como as do bom comportamento e a divisão de tarefas em domésticas e externas, trabalho e lazer, que a sociedade tradicional espera que gênero feminino perpetue. (LOBO, 2007, p. 79)
\end{abstract}

Assim, vozes antes silenciadas, ainda que por vezes provisoriamente, agora têm um espaço que dá margem ao diálogo com o leitor, esse talvez também ficcional, muitas vezes anônimo, mero fingimento de alguém. Mais ainda, esse cenário de vozes que se fazem públicas e cada vez mais conscientes de si permite ao leitor qual (ou quais) texto(s) vai ler, permite o acesso ao texto, o acesso à opinião sobre o texto. Dessa maneira, o leitor vai formando sua "estante" de autores favoritos, seu próprio cânone, sem depender da legitimação de instâncias maiores. Ao fazer isso, ele reorganiza o sistema, ampliado agora como "literatura em rede", com autores-obrasleitores em reiteração, hiperlincagem e retroalimentação. O leitor contemporâneo, liberto de grilhões institucionais, contesta tudo ao se perceber capaz de escolha a negar uma tutela, ou nas palavras de Sartre:

Tal é, pois, a "verdadeira" e "pura" literatura: uma subjetividade que se entrega sob a aparência de objetividade, um discurso tão curiosamente engendrado que equivale ao silêncio; um pensamento que se contesta a si 
mesmo, uma Razão que é apenas a máscara da loucura, um Eterno que dá a entender que é apenas um momento de História, um momento histórico que, pelos aspectos ocultos que revela, remete de súbito ao homem eterno; um perpétuo ensinamento, mas que se dá contra a vontade expressa daqueles que ensinam. (SARTRE, 2004, p. 28)

\section{LITERARY BLOG: A FEW NOTES}

ABSTRACT: As the construct of literature has been subject to discussions and reconstructions throughout history, it seems important to discuss the idea of writing the self in "postmodernity" as a possible revisit to ficcionality and literarity in texts available online, especially those in blogs. The particular and traditional subjective expression surviving many times only in intimate diaries and never published on paper, such writings have found on the internet a very successful place to echo voices that were silent until now. This aspect will be emphasized in this paper as well as we will try to ponder out the canonicity of literary texts and the blog configured as a space for self-reference and publicity of literary writing.

KEYWORDS: Blog. Literarity. Women's writing. Postmodernity

\section{Referências}

AARSETH, Espen J. Cybertext - Perspectives on Ergodic Literature. Baltimore: The Johns Hopkins U P, 1997.

ABREU, Márcia. Cultura letrada. Literatura e leitura. São Paulo: Unesp, 2006.

ARFUCH, Leonor. (Auto)biografía, memoria e historia. Clepsidra. Revista Interdisciplinaria de Estudios sobre Memoria, 1 (março 2014): p. 68-81.

AZEVEDO, Luciene. Blogs: a escrita de si na rede dos textos. Matraga, v.14, n.21, (jul./dez. 2007): p. 44-55. Disponível em http://www.pgletras.uerj.br/matraga/ matraga21/arqs/matraga21a03.pdf

BUURMA, Rachel Sagner; HEFFERNAN, Laura. The Common Reader and the Archival Classroom: Disciplinary History for the Twenty-First Century. New Literary History, vol. 43, n. 1 (2012): p. 113-135.

CASTELLS, Manuel. Redes de indignação e esperança. In: MORAES, Dênis de (org.) Por uma Outra Comunicação. Rio de Janeiro: Record, 2003.

. A sociedade em rede: do conhecimento à política. In: CASTELLS, Manuel; CARDOSO, Gustavo. A sociedade em rede: do conhecimento à acção política. Lisboa: Imprensa Nacional, 2005. p. 17-30.

. Redes de indignación y esperanza. Madrid: Alianza, 2012. 
CORRÊA, Regina M. A. "De Anjos Virtuais e Reais: Mistificação, Paranoia ou uma Questão Cultural?" In: CORREAA, Alamir Aquino, (org). Ciberespaço: mistificação e paranoia. Londrina: Universidade Estadual de Londrina, 2008.

DI LUCCIO, Flavia; NICOLACI-DA-COSTA, Ana Maria. Blogs: De Diários Pessoais a Comunidades Virtuais de Escritores/leitores. Psicologia Ciência e Profissão (Brasília), vol. 30, n. (1), 2010, 132-145. Disponível em http://www.scielo.br/pdf/pcp/v30n1/v30n1a10.pdf

DI LUCCIO, Flavia; NICOLACI-DA-COSTA, Ana Maria. Hipertexto, blogs e leitores escritores. In: RETTENMAIER, Miguel; RÖSING, Tania, (orgs.) Questões de literatura na tela. Passo Fundo: Editora Universidade de Passo Fundo, 2010b. p. 92-110.

DOUBROVSKY, Serge. Fils. Paris: Galilée, 1977.

DURHAM, Meenakshi Gigi; KELLNER, Douglas M, (orgs.). Media and cultural studies: keyworks. Oxford: Blackwell, 2006.

FERNANDES, Hercília Maria. Voz poética feminina na era blog: "Os casos da Maria Clara. Revista Línguas \& Letras (Cascavel), vol. 12, n. 23, 2011, p. 187-212. Disponível em http://e-revista.unioeste.br/index.php/linguaseletras/article/view/5254/ 4910.

GENDOLLA, Peter; SCHÄFER, Jörgen. Playing with signs: towards an aesthetic theory of net literature. In: GENDOLLA, Peter; SCHÄFER, Jörgen, (orgs.) The Aesthetics of Net Literature. New Brunswick: Transaction, 2007. p. 17-42.

HALL, Stuart. A identidade cultural na pós-modernidade. Rio de Janeiro: DP\&A, 2006.

HAYLES. N. Katherine. Electronic literature: new horizons for the literary. Notre Dame: U of Notre Dame P, 2008.

JAMESON, Frederic. Postmodernism, Or, The Cultural. Logic of Late Capitalism. New Left Review (Londres), 146 (1984, jul.-ago.): p. 59-92.

JUVAN, Marco. On Literariness: From Post-Structuralism to Systems Theory. CLCWeb: Comparative Literature and Culture 2.2 (2000). Disponível em http://docs.lib.purdue.edu/clcweb/vol2/iss2/.

KERMODE, Frank. "Institutional Control of Interpretation," Salmagundi 43 (1979): p. 72-87. 
LAKOFF, Robin. Linguagem e lugar da mulher. (1973) In: Lakoff, Robin et al. Linguagem, gênero, sexualidade: clássicos traduzidos. São Paulo: Parábola Editorial, 2010.

LOBO, Luiza. Segredos públicos: os blogs de mulheres no Brasil. Rio de Janeiro: Rocco, 2007.

MAGNABOSCO, Gislaine Gracia. O blog como um hipergênero constelar. In: Revista Linguasagem (São Carlos), 15, Disponível em http://www.letras.ufscar.br/linguasagem/edicao15/002.pdf.

MASON, Stuart. Oscar Wilde - art and morality: a defence of The picture of Dorian Gray. London: J. Jacobs, 1908. Disponível em http://www.gutenberg.org/ebooks/33689.

MATOS, Adriana Dória. Escritores de blogs: a web como espaço de criação e discussão sobre literatura. Hipertextus Revista Digital, 3, 2009. Disponível em http://hipertextus.net/volume3/Adriana-Doria-MATOS.pdf.

MICALIZZI, Alexandra. Personal blogs and mourning: the writing of Self on the Net as a support network in situations of help. Ratio Sociologica (Pescara), vol. 2 , n. I, 2009, p. 43-56. Disponível em

https://www.academia.edu/2331390/Personal_blogs_and_

Mourning_the_writing_of_self_on_the_Net_as_a_support_etwork_in_situations_of_h elp.

PERRONE-MOISÉS, L. Altas Literaturas: escolha e valor na obra crítica de escritores modernos. São Paulo: Companhia das Letras, 1988.

RODRIGUES, Catarina. Blogs: uma ágora na net. Agora.net - Revista sobre Novos Media e Cidadania (Covilhã), 4, [2004]. Disponível em http://www.labcom.ubi.pt/files/agoranet/04/rodrigues-catarina-blogs-agorana-net.pdf

SARTRE, Jean-Paul. O que é literatura? Trad. Carlos Felipe Moisés. São Paulo: Ática, 2004.

SCHITTINE, Denise. Blog: comunicação e escrita íntima na internet. Rio de Janeiro: Civilização Brasileira, 2004.

VARGAS LLOSA, Mario. La verdad de las mentiras. Lima: PEISA, 1993.

VIEGAS, Ana Cláudia. Escritas contemporâneas: literatura, internet e a "invenção de si". Cadernos de Letras da UFF, vol. 32 (Letras \& Infovias), 2006. Disponível em http://www.uff.br/cadernosdeletrasuff/32/artigo4.pdf.

ZELLER, Daniel. A qui appartient la responsabilité de conserver les blogues. Les archives de l'intimité : des journaux intimes aux blogues, 24ème Séminaire 
annuel de Groupe des archivistes de la région de Montréal (GARM), 2011.

Disponível em https://docs.google.com/file/d/0B-

cL1_OrXbEFRnB6a1dzd0RJUG8/edit

Texto recebido em: 22/01/2015.

Texto aceito em: 02/06/2015. 